\title{
EuGMS survey on structures of geriatric rehabilitation across Europe
}

\author{
Stefan Grund ${ }^{1}$ · Janneke P. van Wijngaarden ${ }^{2} \cdot$ Adam L. Gordon $^{3} \cdot$ Jos M.G.A. Schols $^{4}$ • Jürgen M. Bauer ${ }^{1}$
}

Received: 2 August 2019 / Accepted: 5 November 2019 / Published online: 10 December 2019

(c) The Author(s) 2019

\section{Key summary points}

Aim The aim of this study is to provide an overview on structures of geriatric rehabilitation across Europe.

Findings We observed major differences among EuGMS member countries with regard to the availability of geriatric rehabilitation and how it was organized. Despite various barriers in most countries, future improvement in geriatric rehabilitation services is anticipated.

Message Work now needs to focus on establishing a consensus on what geriatric rehabilitation should look like to further geriatric rehabilitation services in all European countries.

\begin{abstract}
Purpose Geriatric rehabilitation provides effective multidisciplinary treatment for older people who show symptoms of relevant and potentially reversible functional decline. The aim of this study is to provide an overview on structures of geriatric rehabilitation across Europe.

Methods All European Geriatric Medicine Society (EuGMS) Full board members, each representing one member state of the society, were asked to complete an online questionnaire about the current structure of geriatric rehabilitation in their country. Results Thirty-one out of 33 EuGMS Full Board members participated in this questionnaire. Geriatric rehabilitation was officially recognized in 65\% (20/31) of participating countries while $29 \%$ (9/31) had no geriatric rehabilitation services in their country. In countries with geriatric rehabilitation, the number of available beds varied widely $(0-70 / 100,000$ inhabitants). Average length of stay varied from 7 to 65 days. The estimated mean age of the patients in geriatric rehabilitation was 80 years, with most patients being older than 70 years. Six countries had no specified lower age limit and no country had an upper age limit. $42 \%$ (13/31) of countries reported having national or local guidelines and 35\% (11/31) had a benchmarking or audit system established. Most participants responded positively about the prospects for improvement in the field.

Conclusion We observed major differences among EuGMS member countries with regard to the availability of geriatric rehabilitation and how it was organized. Despite various barriers in most countries, future improvement in geriatric rehabilitation services is anticipated.
\end{abstract}

Keywords Geriatric rehabilitation · Structure of supply $\cdot$ EuGMS $\cdot$ European consensus

Stefan Grund

stefan.grund@bethanien-heidelberg.de

Jos M.G.A. Schols

jos.schols@maastrichtuniversity.nl

https://hsr.mumc.maastrichtuniversity.nl/

https://www.LPZ-UM.eu

1 Center for Geriatric Medicine, Agaplesion Bethanien Hospital Heidelberg, Geriatric Center at the Heidelberg University, Rohrbacher Straße 149, 69126 Heidelberg, Germany

2 Danone Nutricia Research, Nutricia Advanced Medical Nutrition, Uppsalalaan 12, 3584 CT Utrecht, The Netherlands
3 Division of Medical Sciences and Graduate Entry Medicine, Derby Medical School, Royal Derby Hospital, University of Nottingham, Room 4113, Derby DE22 3NE, UK

4 Departments of Health Services Research, Focusing on Value-based Care and Ageing and Family Medicine, Care and Public Health Research Institute (Caphri), Maastricht University, Duboisdomein 30, 6229 GT, 6200 MD, P.O. Box 616, Maastricht, The Netherlands 


\section{Introduction}

Due to population aging, the number of older patients with frailty across Europe is increasing [1]. Such patients are characterized by vulnerability to functional decline in the context of acute and/or chronic comorbidities [2]. The main aim of geriatric rehabilitation is to restore function [3] and several studies have shown it to improve outcomes, in terms of the number of patients sufficiently independent to return home following intervention [4-7]. Geriatric rehabilitation is likely to represent an important part of how health systems respond to the demographic imperative. To date, there has been no systematic analysis of the structures for geriatric rehabilitation across Europe. To provide a basis for future service development in geriatric rehabilitation, we set out to describe geriatric rehabilitation structures in place across Europe.

\section{Methods}

An online survey was designed to collect information on the structures of geriatric rehabilitation across Europe. Questions were structured under the headings: general structural aspects and treatment capacities, patient population and rehabilitation team structure, treatment standards and guidelines, financial structure, and facilitators and barriers to the development of geriatric rehabilitation.

Specific questions focused on the national capacity for in- and outpatient geriatric rehabilitation, number of beds and average length of stay. Additional questions covered the configuration of the geriatric rehabilitation team, and the use and availability of benchmarks and guidelines. The average age, main indications for admission as well as the percentage of hip fracture patients and frequent fallers were queried. Finally, responses were sought on barriers for the future development of geriatric rehabilitation. The full questionnaire is provided in Appendix: EUGMS questionnaire "geriatric rehabilitation in Europe" section.

The survey was formatted using Google Forms and was sent out in April 2018 by the European Union Geriatric Medicine Society (EuGMS) office to the official representatives of the 33 European Geriatric Medicine Society (EuGMS) Full Board Member States. These are Austria, Belarus, Belgium, the Czech Republic, Denmark, Estonia, Finland, France, Germany, Greece, Hungary, Ireland, Iceland, Israel, Italy, Latvia, Lithuania, Luxembourg, Malta, Norway, Poland, Portugal, Romania, Russia, Serbia, Slovakia, Slovenia, Spain, Sweden, Switzerland, the Netherlands, Turkey and the United Kingdom. Where respondents' responses were unclear, clarification was sought by follow-up email.

Quantitative variables were expressed as means and standard deviations (SD) where normally distributed, or median and interquartile range (IQR) where not normally distributed. To calculate numbers per 100,000 inhabitants, population data from the EuGMS homepage were used [8].

\section{Results}

\section{Data collection}

$31 / 33$ (94\%) member state representatives completed the online questionnaire with no response from Slovakia and Latvia. 26/31 (87\%) respondents were geriatricians. Other respondents were a physiatrist (Turkey), an elderly care physician (the Netherlands), an internist (Slovenia) and a neurologist (Greece)

(a) Geriatric rehabilitation structures in EUGMS member states

\section{Formal recognition of geriatric rehabilitation}

In most (20/31) of the participating EuGMS member states, geriatric rehabilitation was formally recognized by the national geriatric society. Spain, Serbia and Belarus had geriatric rehabilitation services but geriatric rehabilitation was not formally recognized. In contrast, in Poland geriatric rehabilitation was recognized but there were no geriatric rehabilitation services. In Switzerland, geriatric rehabilitation was recognized by the Swiss Geriatrics Society and there were active departments, but it was not acknowledged by the health insurance companies and was not covered by their policies. Eight countries-Norway, Estonia, Lithuania, Czech Republic, Slovenia, Hungary, Portugal and Greece-reported no formal recognition for geriatric rehabilitation in their countries and no specialist departments working in the field (Fig. 1).

\section{General geriatric rehabilitation structure}

Seventy one percent of EuGMS member states (22/31) provided geriatric rehabilitation for inpatients and outpatients. Italy provided inpatient rehabilitation only. Inpatient GR is provided in nursing homes, geriatric rehabilitation centers, geriatric rehabilitation hospitals, and acute care hospitals.

\section{Capacity for inpatient geriatric rehabilitation}

France reported the highest number of departments for geriatric rehabilitation $(n=500)$, followed by Germany $(n=170)$ (Fig. 2a). Relative to the number of inhabitants, Iceland had the most facilities with one department per 100,000 inhabitants, closely followed by the Netherlands and France, with 0.85 and 0.75 departments per 100,000 inhabitants, respectively. The smallest numbers of facilities per capita were in 

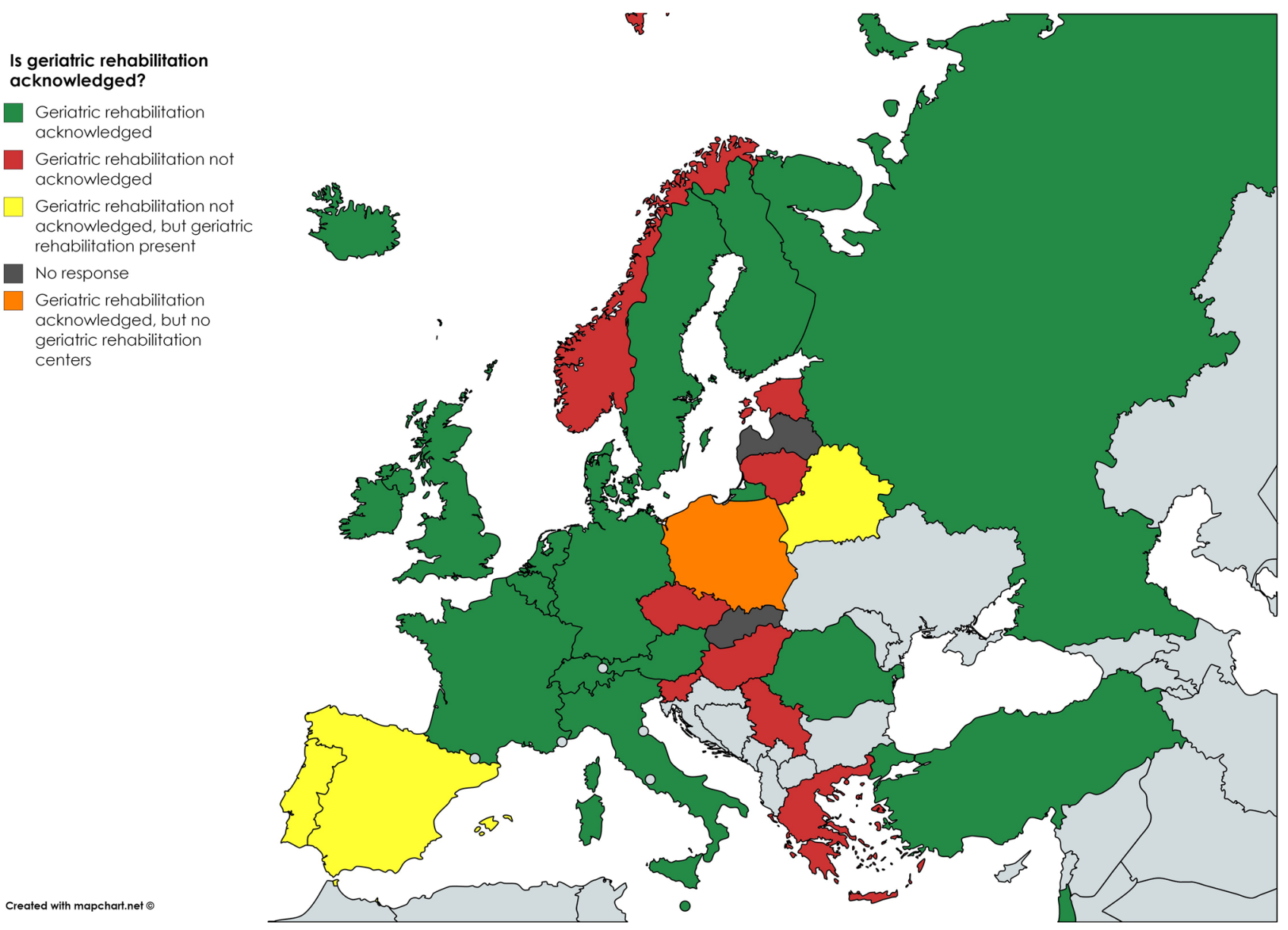

Fig. 1 Acknowledgement of geriatric rehabilitation

Italy $(0.003 / 100,000)$ and Turkey $(0.004 / 100,000)$ (median $0.36 / 100,000 ;$ IQR 0,65) $(N=17)$ (Fig. 2b). The respondents from the United Kingdom, Switzerland and Denmark could not provide the precise number of geriatric rehabilitation departments for their countries.

Belgium reported the highest number of available beds per capita for geriatric rehabilitation $(70 / 100,000)$, followed by Malta $(60 / 100,000)$ and Iceland $(48 / 100,000)$. The lowest numbers of beds per capita were found in Italy $(0.07 / 100,000)$ and Turkey $(0.13 / 100.000)$ (median 17/100.000; IQR 36) $(N=18)$ (Fig. 2c). No precise numbers were available for Switzerland, Denmark, and Romania.

The average length of stay for inpatient geriatric rehabilitation varied from 7 days in Denmark and 8 days in Sweden to 40 days in the Netherlands and 65 days in Malta (median 22 days; IQR 15) ( $N=23)$ (Fig. 2d).

\section{Sub-specialty geriatric rehabilitation}

Fourteen of the 22 countries with geriatric rehabilitation facilities reported the existence of specialist departments for specific geriatric rehabilitation sub-populations. Eight had specialist units for stroke patients, seven for orthopedic and hip fracture patients, five for cognitively impaired patients, three for other neurological conditions including Parkinson`s disease, three for pulmonary conditions, one for cardiac conditions and one for oncological diseases.

\section{Capacity for outpatient geriatric rehabilitation}

The number of geriatric outpatient rehabilitation departments varied from 1 in Romania to around 200 in Finland, Sweden and France. Finland had the highest relative number of facilities per capita with 3.64/100,000 inhabitants, closely followed by Sweden $(2 / 100,000)$. The lowest number of outpatient geriatric rehabilitation facilities in countries with geriatric rehabilitation was reported for Romania $(0.01 / 100,000)$ (Fig. 3a).

The length of attendance in outpatient geriatric rehabilitation varied from 10 days in Estonia and Austria to 90 days in Belgium and 180 days in Serbia (median 20; IQR 26) $(N=19)$ (Fig. 3b).

(b) Patients and Indications 
a

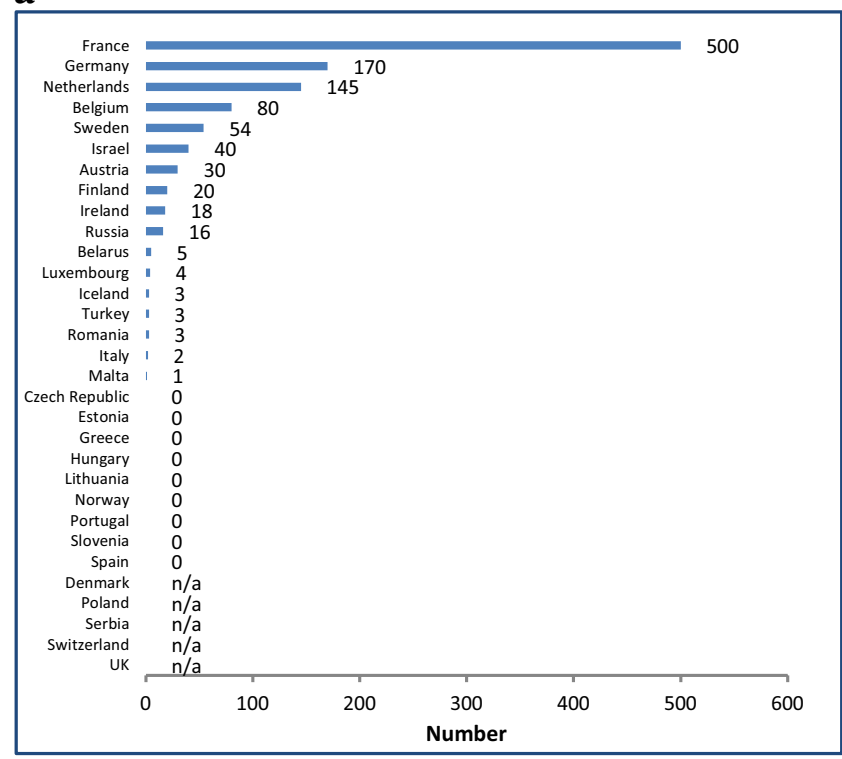

c

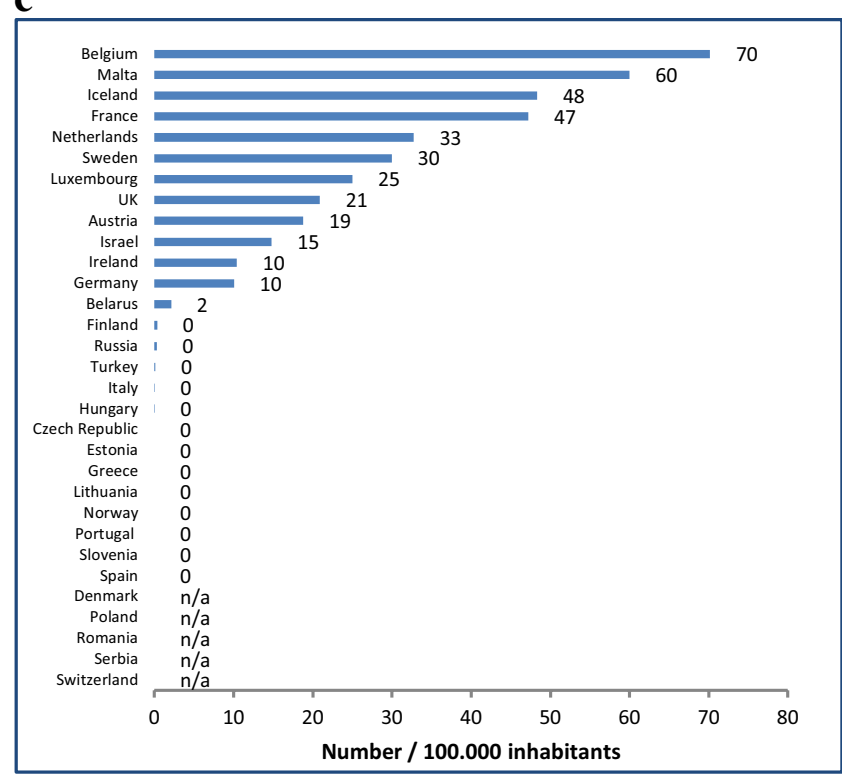

b

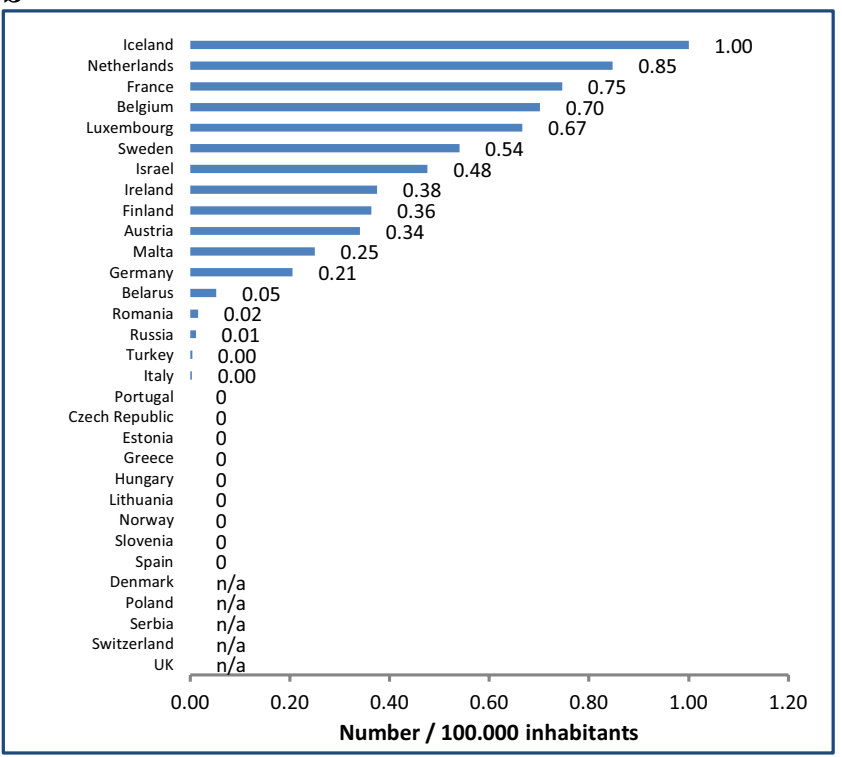

d

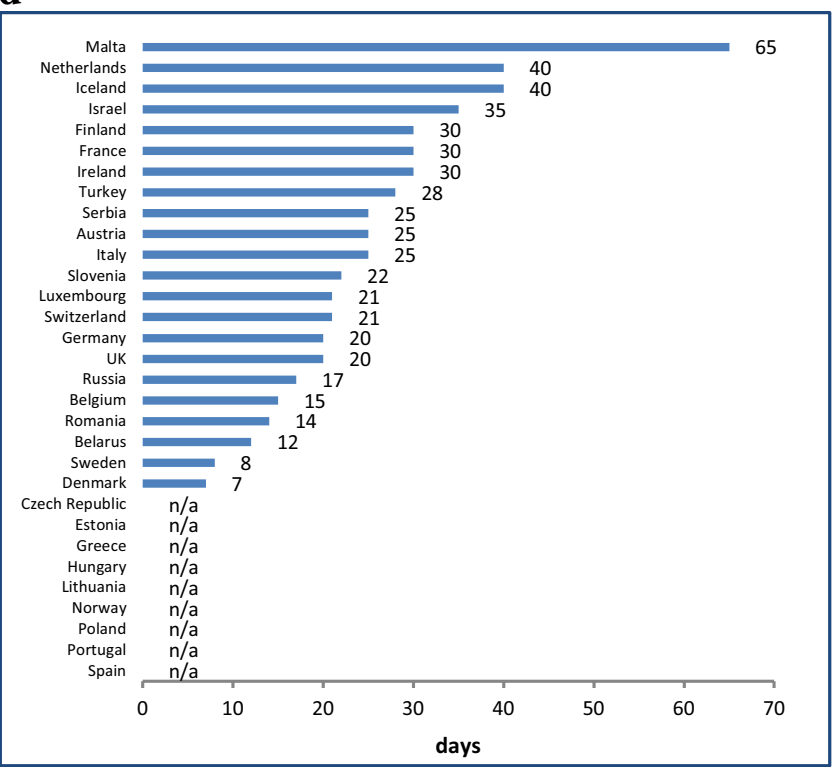

Fig. 2 Capacities of inpatient geriatric rehabilitation. a Departments of GR (total numbers). b Departments of GR (per 100.000 inhabitants). c Beds of GR (per 100.000 inhabitants). d Length of stay (days)

The estimated mean age for geriatric rehabilitation patients in all participating countries was 80 (SD 4,3) years $(N=23)$. Only $30 \%$ of the countries where geriatric rehabilitation was recognized had a lower age limit. Where one was in place it was consistently set between 60 and 65 years. No country reported an upper age limit.

Seventeen respondents provided information on the main conditions triggering admission to geriatric rehabilitation. The most frequent reported were stroke in $65 \%$ of respondents, deconditioning/frailty/multimorbidity (condition complex) in $53 \%$ of respondents, hip fracture in 53\% of respondents, and repeated falls in $41 \%$ of respondents. An overview of the main indications for admission is provided in Fig. 4.
Cognitively impaired patients were excluded from rehabilitation treatment in $9(29 \%)$ responding countries $(N=31)$ and in $3(15 \%)$ of the countries which formally recognize geriatric rehabilitation.

(c) Geriatric team structure and treatment goals

Ninety-five percent (19/20) of countries with recognized geriatric rehabilitation had teams led by a geriatrician or elderly care physician. 20 countries listed the following members of the multidisciplinary geriatric rehabilitation team: nurses (19/20 countries), physiotherapists (20/20 countries), occupational therapists (17/20 countries), speech therapists 
a

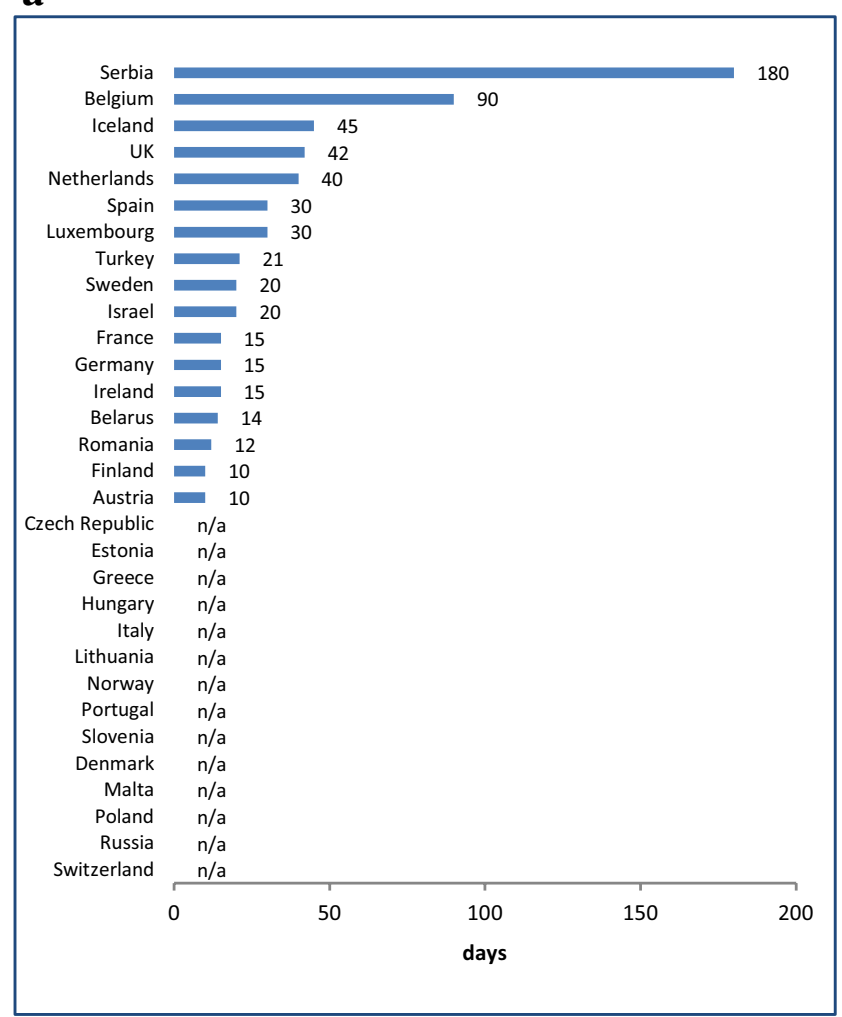

b

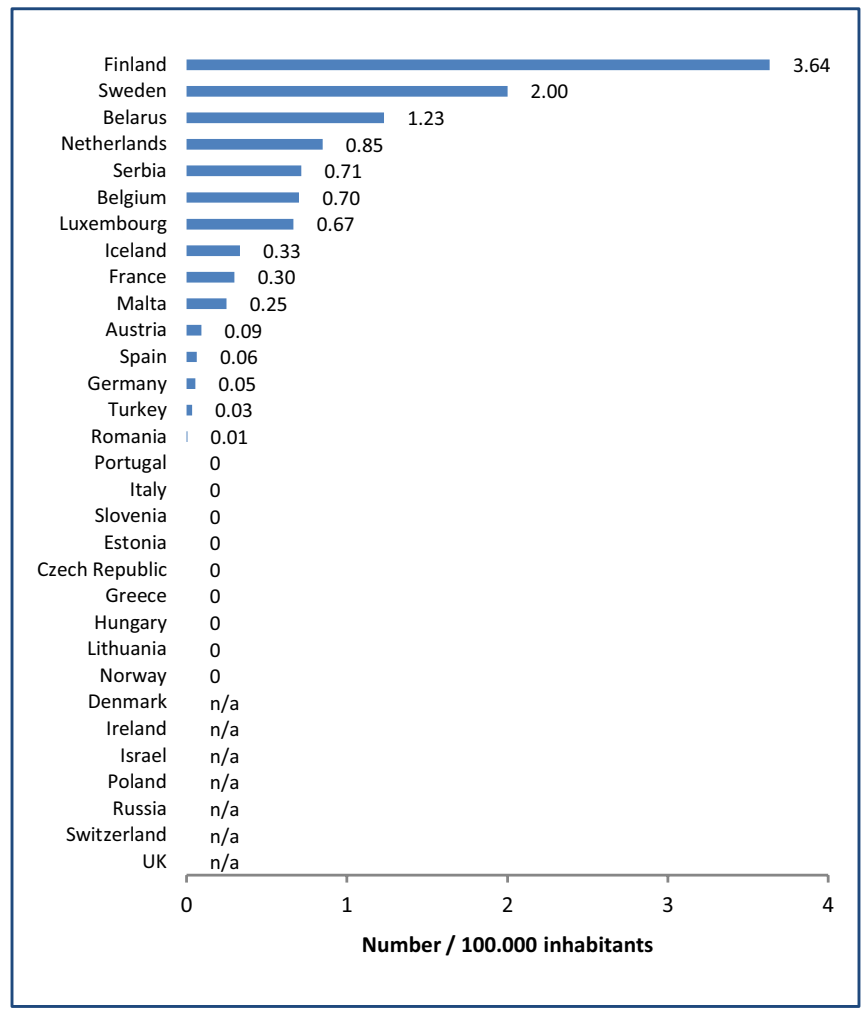

Fig. 3 Capacities of outpatient geriatric rehabilitation. a Departments of GR (per 100.000 inhabitants). b Length of stay (days)

(16/20 countries), social workers ( $15 / 20$ countries), dieticians (13/20 countries) and psychologists (4/20 countries).

(d) Standards and guidelines for geriatric rehabilitation

Fifty-five percent (11/20) of countries which recognized geriatric rehabilitation had national or local guidelines in use (Fig. 5a).

A benchmarking system or a systematic evaluation of geriatric rehabilitation was in place in 11/20 (55\%) of countries which recognized geriatric rehabilitation (Fig. 5b).

\section{Definition of treatment goals}

$17 / 20(85 \%)$ of the countries where geriatric rehabilitation was recognized aimed to define treatment goals within the first days of geriatric rehabilitation.

\section{Screening for malnutrition}

$16 / 20(80 \%)$ of the countries where geriatric rehabilitation was recognized indicate that they screened for malnutrition (Fig. 5c) and specified the screening tool as: Mini Nutritional Assessment (MNA) in 12/16 countries, Malnutrition Universal Screening Tool (MUST) in 2/16 countries,
Simplified Nutritional Assessment Questionnaire (SNAQ) in $1 / 16$ countries and unspecified in $1 / 16$ countries.

(e) Financial structure

A public health insurance system was available in all participating countries; geriatric rehabilitation was covered by this in all countries where it was formally recognized with the exception of Switzerland. 3/20 countries where rehabilitation was recognized stated that the rehabilitation patients have to pay a small part of the rehabilitation costs.

(f) Barriers to geriatric rehabilitation, and future perspectives of geriatric rehabilitation in Europe

\section{Barriers to geriatric rehabilitation}

Eighty-one percent (25/31) of all responding countries stated that they observed barriers for geriatric rehabilitation.

\section{Economic barriers}

Financial barriers were observed in 9/31 (29\%) of countries. Examples from the free text included from Hungary, where 
Fig. 4 Main condition groups in geriatric rehabilitation

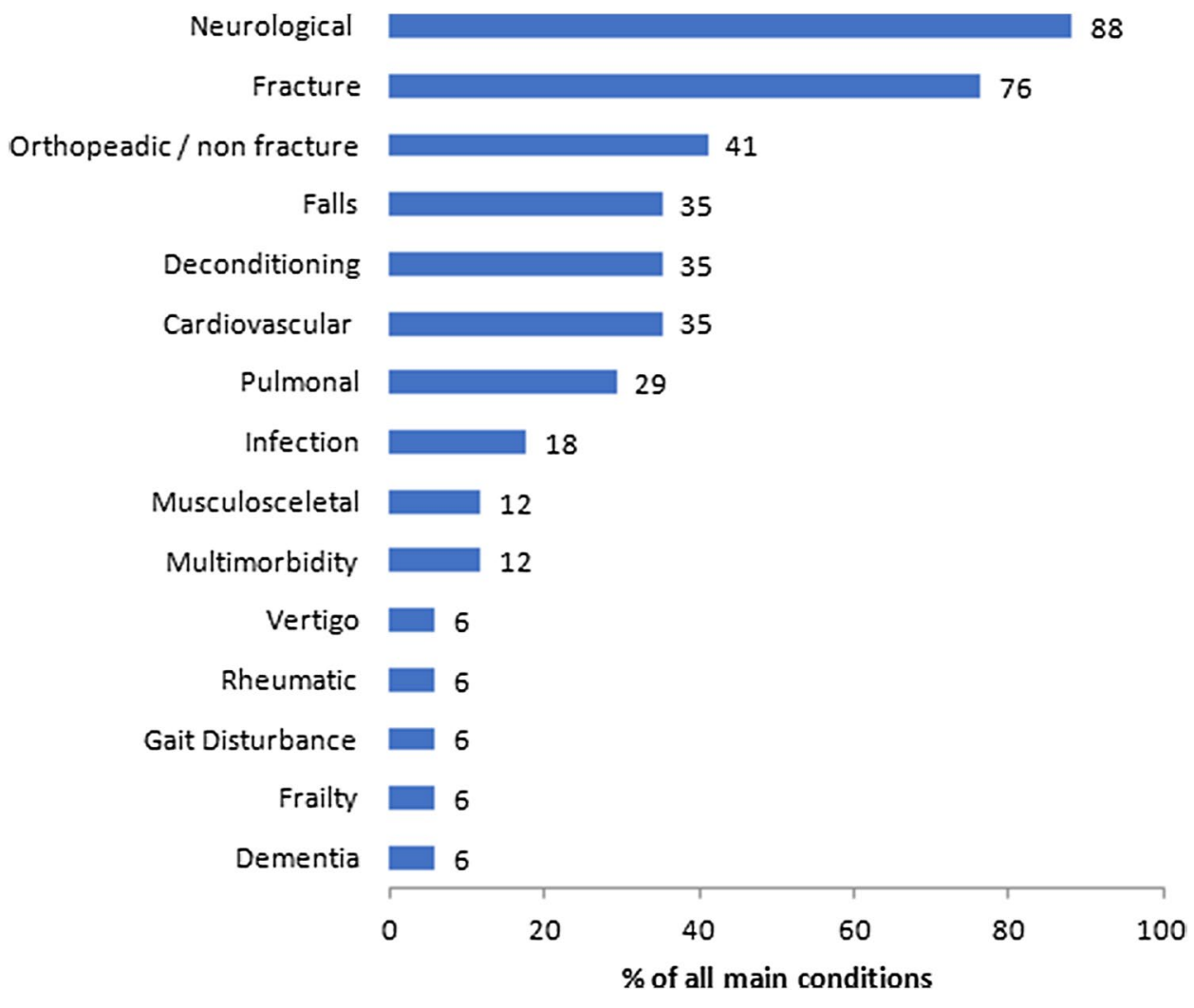

Health care structural barriers

geriatric rehabilitation“...is no[t] accepted as a special, age-dependent intervention in [the] state health financing system”. In Germany, "There are some barriers concerning the approval of geriatric rehabilitation by the public health insurances". In Turkey, there was "not enough reimbursement." In the UK, the respondent acknowledged the, "...limits of a resource-restrained state-funded healthcare system".

\section{Staff related barriers}

Staff-related barriers were reported by $3 / 31$ (10\%) of countries. The Irish respondent cited "staffing shortages", whilst the Israeli respondent focused on "Lack of qualified staff (nurses, physicians, etc.)," and the UK respondent stated that, "More trained geriatricians and geriatric MDT members are required."

\section{Political barriers}

9/31 (29\%) of countries reported political barriers. The Norwegian respondent stated that there, “...is no national strategy for geriatric rehabilitation." In Iceland, there were recognized issues with, "political prioritizing decisions." In Switzerland, there was "No political will to finance geriatric rehabilitation." In the UK, a more nuanced difficulty was expressed, where "The distinction between rehabilitation and reablement is not always constructive and lies, in part, with the artificial cleavage between health and social care."
$10 / 31(32 \%)$ of countries cited barriers related to health care structures. In Spain, "The number of beds for the geriatric rehabilitation is deficient and not integrated into geriatric or rehabilitation departments. There are different settings with a heterogeneous structure and organization.” In Romania, "[The] main barrier is the lack of a coherent Geriatric Medicine network. Geriatric Medicine services are not evenly distributed. Large areas with [a] high percentage of older patients do not have any Geriatric Medicine facility." In Austria, "different structures in different provinces [mean that] there are only good structures in four, and none in two provinces." In the UK, "Duration of therapy is frequently determined by what the service can provide rather than by the needs of individual patients or what is technologically possible."

\section{Other barriers}

4/31 (13\%) countries recognized other barriers. In Greece, there were issues with conflict between specialties manifesting as, "Resistance of Physiatrists to give such patients to geriatricians for rehabilitation." In Belarus, a major problem was the, "lack of national guidelines on geriatric rehabilitation." In Malta, there was an issue with awareness of geriatric rehabilitation amongst other healthcare professionals, meaning that "Family doctors might not be aware of the 
a
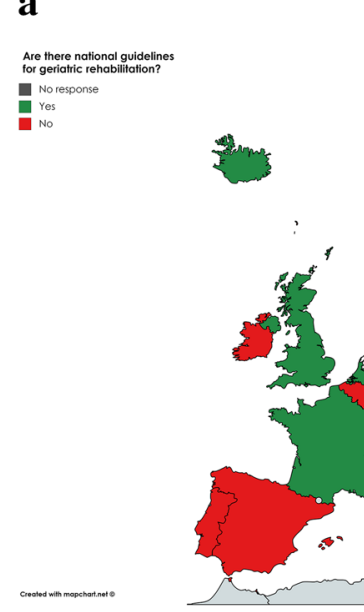

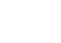

ข. b

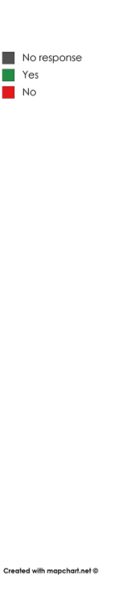

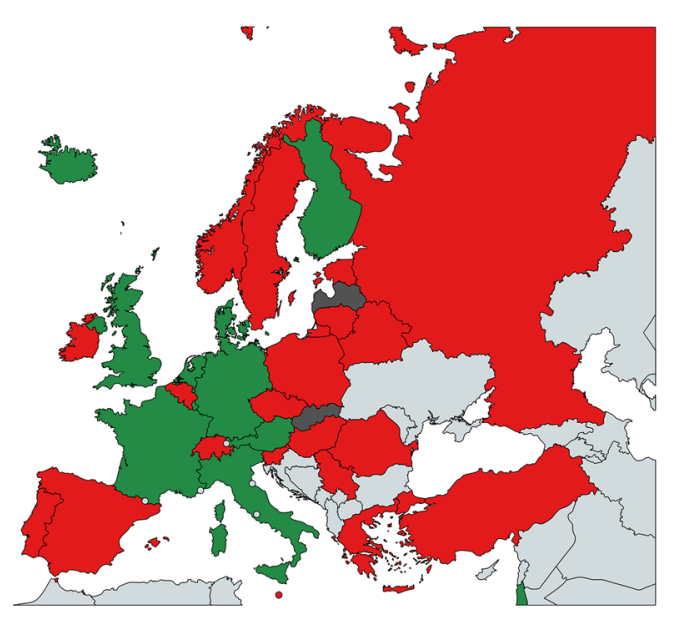

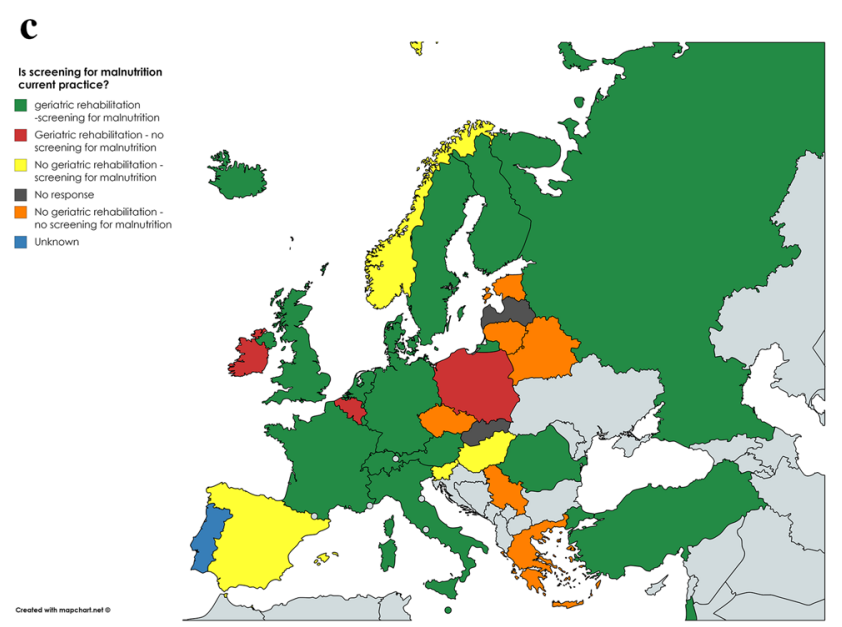

Fig. 5 Standards and guidelines for geriatric rehabilitation. a National guidelines for geriatric rehabilitation. b Systematic evaluation for geriatric rehabilitation. c Screening for malnutrition in geriatric rehabilitation

services offered. This might change [now that] trainee family doctors spend a time with the geriatrics department."

\section{Trends/future perspectives}

20/31 (65\%) of the countries were positive about the future, observing a positive trend toward the establishment of geriatric rehabilitation. Two countries were negative about the future. Seven countries were uncertain and two countries did not answer this question.

\section{Discussion}

This study illustrates the differing status of GR in countries across Europe. Important differences include the recognition of GR by the national Society for Geriatric Medicine, the available bed base per capita for GR and average length of stay. In some countries, GR structures are absent or partially lacking, with this being particularly the case in countries where the speciality is not formally recognized.

When the resource available for GR, in terms of available staff and bed base, is compared with other forms of medical rehabilitation, then it becomes particularly clear how poorly resourced it is. Taking Germany as an example, there are 1149 preventive and rehabilitation facilities, caring for patients with a mean age of 51.6 years [9], compared with 170 facilities providing geriatric rehabilitation. This inequity will only become more pronounced as population aging continues.

The similarities between countries regarding GR largely relate to the people who receive and deliver GR. The indications for inclusion into GR were similar across countries and comprise mainly geriatric syndromes and their negative impacts [10]. The core GR team composition, comprising a geriatrician or skilled elderly care physician, nurses and physiotherapists, was also similar across Europe and matched the findings of previous Delphi study [11]. 
Wide differences in length of stay between countries are explained by the different settings and forms of GR, the different ways it is conducted, as well as the way that GR is funded and regulated in different countries. There is no consensus between countries on the lower age limit for GR patients. There are widely differing approaches to the inclusion of cognitively impaired patients, despite evidence that they can benefit from appropriately structured GR [12-14]. This lack of consensus is an additional barrier to the development of GR. Work to develop expert consensus would provide a more solid foundation for professionals as they work to develop patient care.

The strength of this paper is that it used the organisational structures of the EuGMS to ensure an authoritative and representative response across member states. The very high response rate reflects the overall high interest in this topic and reinforces the importance of this survey. The limitations of the survey are that the necessary breadth meant that it was difficult to develop a detailed understanding of rehabilitation in each country. The need to draw comparison between nations with differing structures of care, as well as the linguistic issues faced by conducting the survey in English, may have affected the accuracy and precision of some responses. Respondents were only able to answer using available data from their country, which meant that not all respondents were able to answer all questions. It is possible that asking only one respondent to summarize the situation for an entire country may have led to some oversights, but we did our best to track down authoritative respondents using the delegation infrastructure of the national societies through the EuGMS full board.

\section{Conclusion}

In conclusion, this is the first investigation of structures for geriatric rehabilitation across Europe. We observed large differences between countries with regard to how geriatric rehabilitation was structured and delivered. Several countries did not formally recognize geriatric rehabilitation through their local geriatric society and in these countries there were limited or no structures for geriatric rehabilitation. The targeted patient groups for geriatric rehabilitation, and the professionals involved, showed a significant overlap between the countries. Some countries were clearly very structured in their approach to GR, with published guidelines and benchmarking processes. Work now needs to focus on establishing a consensus on what GR should look like. This can then be used as a basis for service development and for practitioners across the continent to learn from the exemplary practice already in place in some countries.

Acknowledgements The authors would like to thank all the respondents of this survey for filling out the questionnaire and the following correspondences, the Executive Board of the EuGMS for giving the opportunity to undertake this study, to Benedetta Belotti (EuGMS secretariat) for their support to contact and correspondence with the respondents of the survey. The authors would like to thank Yvette Luiking for their support in accompanying the design of the survey and reviewing the manuscript.

\section{Compliance with ethical standards}

Conflict of interest This work was financially supported by Nutricia Research, Nutricia Advanced Medical Nutrition. Janneke van Wijngaarden, Yvette Luiking are Nutricia Research employees. Stefan Grund, Adam Gordon, Jos MGA Schols, Jürgen M Bauer have no conflict of interest to declare.

Ethical approval Ethical approval of a medical ethics committee (MEC) is not required for the present study in any home country of the author and co-authors.

Informed consent Informed consent is not required for the present study in any home country of the author and co-authors.

Open Access This article is distributed under the terms of the Creative Commons Attribution 4.0 International License (http://creativeco mmons.org/licenses/by/4.0/), which permits unrestricted use, distribution, and reproduction in any medium, provided you give appropriate credit to the original author(s) and the source, provide a link to the Creative Commons license, and indicate if changes were made.

\section{Appendix: EUGMS questionnaire "geriatric rehabilitation in Europe"}

Dear colleague,

We cordially invite you to participate in this survey on the structures and the practice of geriatric rehabilitation across Europe.

To our current knowledge, the structures of geriatric rehabilitation differ widely among European countries. Up to now, no systematic survey has been realized in this regard. Therefore, we intend to undertake this important task. The results of this survey will be presented on the next EUGMS conference in Berlin, October 2018, and published in our journal European Geriatric Medicine in 2018. This will help geriatricians, scientists and politicians alike to understand where local deficits may be found and how geriatric rehabilitation might be developed in their country.

The questionnaire consists of five main questions, with sub questions. The questionnaire needs to be filled out in one session; it is not possible to save your answers in between. It takes around 30-45 min to complete the questionnaire.

If you want to give us some additional—detailed-information, or you have questions, please send us an email: stefan.grund@bethanien-heidelberg.de

Please answer the questions in English.

Thank you for your cooperation!

Kind regards,

The EUGMS Task \& Finish group

*Required 


\section{General questions}

1.

About which country are you filling out this questionnaire? *

2.

What is your profession? *

Mark only one oval.

geriatrician

Other:

\section{Question 1: Which geriatric rehabilitation structures exist in your country? \\ What we mean by 'geriatric rehabilitation' is rehabilitation care specifically for the geriatric population, controlled by a geriatrician or with a geriatrician with medical responsibility for all geriatric patients, including structured care within the community hospitals and rehabilitation centers.}

3. 1a. Is geriatric rehabilitation officially acknowledged e.g. by the geriatric society in your country? *

Mark only one oval.

Yes

No

4.

1b. How many departments for geriatric rehabilitation exist in your country in total? (number) *

5.

1c. How many departments for geriatric rehabilitation have a geriatrician as department head in your country? (number) *

6. 1d. How many beds for geriatric rehabilitation are available in total? (number)

7.

1e. Where are the departments for geriatric rehabilitation located? *

Tick all that apply.

Exclusively in hospitals

Exclusively in specialized rehabilitation facilities

In both settings

Other...

Other: 
1f. Are there sub-departments for specific patient groups in geriatric rehabilitation, like cognitively impaired patients, post stroke? *

Mark only one oval.

Yes

No

9.

If yes, please describe the respective sub-groups:

10. 1g. Is geriatric rehabilitation offered for: *

Mark only one oval.

Inpatients

Outpatients

Inpatients and outpatients

Other:

11.

1h. How many facilities are there for geriatric rehabilitation for outpatients? (number) If none, please fill in ' 0 '. *

12.

Do you have any comments/ extra explanation regarding outpatient rehabilitation?

13.

1i. Which specialists work in your geriatric rehabilitation team: *

Tick all that apply.

$\square$ Geriatrician

Nurse

$\square$ Physiotherapist

$\square$ Speech therapist

$\square$ Social worker

$\square$ Dietician

Occupational therapist

Other: 
14.

Comments on the geriatric rehabilitation structures in your country:

\section{Question 2: Please characterize the geriatric rehabilitation population in your country}

15. 2a. Please indicate which of the following conditions are indications for geriatric rehabilitation in your country: *

Tick all that apply.

Stroke

Musculoskeletal disease

Post elective orthopedic surgery

Post trauma surgery

Neurodegenerative conditions

Oncological conditions

$\square$ COPD

Cardiovascular diseases (besides stroke)

Recurrent falling

$\square$ Other:

16.

What is the percentage of hip fracture patients among all geriatric rehabilitation patients? $(\%)$ *

17.

What is the percentage of frequent fallers among all geriatric rehabilitation patients?

$(\%)$ *

\section{2b. What are the 4 largest patient groups in geriatric} rehabilitation?

please indicate the 4 largest patient groups by indication

18.

Condition 1: 
19.

Condition 2:

20

Condition 3:

21

Condition 4:

22. 2c. In geriatric rehabilitation in your country, do you define treatment goals during the first days of rehabilitation? *

Mark only one oval.

Yes

No

23.

2d. What is the average time frame for inpatient geriatric rehabilitation? (In days) *

24.

2e. What is the average time frame for outpatient geriatric rehabilitation? (In days)

25.

2f. Do you have a lower and/or upper age limit? *

Mark only one oval.

Yes

No

26. $2 \mathrm{~g}$. What is the age limit? If none, please state 'n.a.' *

27. $2 \mathrm{~h}$. What is the average age of people in geriatric rehabilitation? *

28. Comments on the population characterization: 


\section{Question 3. What is the financial structure for geriatric rehabilitation in your country?}

29.

3a. Do you have public health insurance in your country? *

Mark only one oval.

$\bigcirc$ Yes

No

30. 3b. Is public health insurance covering geriatric rehabilitation? *

Mark only one oval.

Yes

No

Not applicable

31.

3c. Is pension insurance covering geriatric rehabilitation? *

Mark only one oval.

Yes

No

Not applicable

32.

3d. Do patients have to pay for geriatric rehabilitation directly? *

Mark only one oval.
Yes
No
Not applicable

33.

Comments on the financial structure of geriatric rehabilitation in your country:

\section{Question 4: What are current} standards/recommendations/guidelines used in geriatric rehabilitation in your country?

34.

4a. Are there national or local standards/guidelines for the assessment and treatment of patients in geriatric rehabilitation in your country? *

Mark only one oval.

Yes

No 
35.

4b. Which standards do you follow and which guidelines do you use? *

36. 4c. Do you screen for nutritional status at admission? *

Mark only one oval.

Yes

No

37.

If yes, which screening tools do you use?

38.

4d. Do you exclude patients with the diagnosis dementia from geriatric rehabilitation treatment? *

Mark only one oval.

Yes

No

39.

Comments on geriatric rehabilitation to cognitively impaired patients:

40.

4e. Is geriatric rehabilitation evaluated in a systematic way in your country? *

Mark only one oval.

Yes

No

41.

If yes, how? 
42. Comments on standards and guidelines:

\section{Question 5: additional questions}

43. 5a. Do you observe a positive or a negative trend towards the establishment of geriatric rehabilitation in your country at the moment? Please explain? *

44. 5b. Do you observe barriers for geriatric rehabilitation in your country? Please explain. *

45. 5c. Can you provide information on useful websites to check on geriatric rehabilitation in your country?

46.

Comments on additional questions:

Powered by

: Google Forms 


\section{References}

1. Duursma S, Castleden M, Cherubini A, Cruz-Jentoft A, Pitkälä K, Rainfray M, Sieber C, Sinclair A (2004) European union geriatric medicine society-position statement on geriatric medicine and the provision of health care services to older people. J Nutr Health Aging 8(3):190-195

2. Covinsky KE, Palmer RM, Fortinsky RH, Counsell SR, Stewart AL, Kresevic D et al (2003) Loss of Independence in activities of daily living in older adults hospitalized with medical illnesses: increased vulnerability with age. J Am Geriatr Soc 51(4):451-458

3. Kane RL, Jette AM, Hamilton BB, Liang MH, Whiteneck G, Kramer AM, Fuhrer MJ, Keith RA, Materson R, Stason WB, Bergstrom N, Duncan P, Laouri M, Johnston MV, Stineman MG, Morrison MH, Morris JN, Leiter P, Markello S, Lohr KN (1997) Boston working group on improving health care outcomes through geriatric rehabilitation. Med Care 35(6:Suppl):JS4-20

4. Bachmann S, Finger C, Huss A, Egger M, Stuck AE, Clough-Gorr KM (2010) Inpatient rehabilitation specifically designed for geriatric patients: systematic review and meta-analysis of randomised controlled trials. BMJ 340:c1718

5. Ellis G, Whitehead MA, Robinson D, O'Neill D, Langhorne P (2011) Comprehensive geriatric assessment for older adults admitted to hospital: meta-analysis of randomised controlled trials. BMJ 343: 6553

6. Kool J, Oesch P, Bachmann S (2017) Predictors for living at home after geriatric inpatient rehabilitation: a prospective cohort study. J Rehabil Med 49(2):185-190

7. Jamour M, Marburger C, Runge M, Sieber CC, Tümena T, Swoboda W (2014) Effectiveness of geriatric rehabilitation in the oldest old. Evaluation of South German observational data. Z Gerontol Geriatr 47(5):389-396. https://doi.org/10.1007/s0039 1-014-0662-5
8. European Union Geriatric Medicine Society (EuGMS). OurMembers/national societies https://www.eugms.org/our-membe rs/national-societies.html. Accessed 26 July 2019

9. Rehabilitation Report 2018-German Pension Insurance https ://www.deutsche-rentenversicherung.de/Allgemein/de/Inhalt/6_ Wir_ueber_uns/03_fakten_und_zahlen/03_statistiken/02_stati stikpublikationen/02_rehabericht_2018.pdf?_blob=publicatio nFile \&v $=2$. Accessed 26 July 2019

10. Inouye SK, Studenski S, Tinetti ME, Kuchel GA (2007) Geriatric syndromes: clinical, research, and policy implications of a core geriatric concept. J Am Geriatr Soc 55(5):780-791. https://doi. org/10.1111/j.1532-5415.2007.01156.x

11. van Balen R, Gordon AL, Schols JMGA, Drewes YM, Achterberg WP (2019) What is geriatric rehabilitation and how should it be organized? A Delphi study aimed at reaching European consensus. Eur Geriatr Med 10:977-987. https://doi.org/10.1007/s4199 9-019-00244-7

12. Hauer K, Schwenk M, Zieschang T et al (2012) Physical training improves motor performance in people with dementia: a randomized controlled trial. J Am Geriatr Soc 60(1):8-15. https://doi. org/10.1111/j.1532-5415.2011.03778.x (Epub 2011 Dec 28)

13. Toba K, Nakamura Y, Endo H et al (2014) Intensive rehabilitation for dementia improved cognitive function and reduced behavioral disturbance in geriatric health service facilities in Japan. Geriatr Gerontol Int 14(1):206-211. https://doi.org/10.1111/ggi.12080 (Epub 2013 May 6)

14. Dutzi I, Schwenk M, Kirchner M, Bauer JM, Hauer K (2017) Cognitive change in rehabilitation patients with dementia: prevalence and association with rehabilitation success. J Alzheimers Dis 60(3):1171-1182. https://doi.org/10.3233/jad-170401

Publisher's Note Springer Nature remains neutral with regard to jurisdictional claims in published maps and institutional affiliations. 